\title{
Bioinspired synthesis of silver nanoparticles from Morus alba and their photocatalytic degradation and antibacterial activity assessment
}

\author{
Muhammad Arshad ${ }^{1}$, Muhammad Ashraf Shaheen ${ }^{2 *}$, Abdul Qayyum³, \\ Maryam Maqsood ${ }^{1}$, Tahir Mehmood ${ }^{4}$, Abdul Karim ${ }^{4}$ and Tauqeer \\ Ahmad $^{2}$ \\ 1. Department of Chemistry, Govt. Post Graduate Islamia College, Gujranwala-Pakistan \\ 2. Department of Chemistry, University of Sargodha, Sub-Campus Mianwali-Pakistan \\ 3. Department of Chemistry, University of Agriculture, Faisalabad-Pakistan \\ 4. Department of Chemistry, University of Sargodha, Sargodha-40100-Pakistan \\ *Corresponding author's email: ashraf.shaheen@uos.edu.pk \\ Citation \\ Muhammad Arshad, Muhammad Ashraf Shaheen, Abdul Qayyum, Maryam Maqsood, Tahir Mehmood, Abdul \\ Karim and Tauqeer Ahmad. Bioinspired synthesis of silver nanoparticles from Morus alba and their \\ photocatalytic degradation and antibacterial activity assessment. Pure and Applied Biology. Vol. 7, Issue 4, pp \\ 1252-1260. http://dx.doi.org/10.19045/bspab.2018.700145
}

\begin{tabular}{|c|c|c|c|}
\hline Received: 15/01/2018 & Revised: $23 / 08 / 2018$ & Accepted: 02/09/2018 & Online First: 06/09/2018 \\
\hline
\end{tabular}

\section{Abstract}

Plant-mediated synthesis of nanomaterials has been gradually gaining popularity due to its costeffectiveness and eco-friendly nature. In the present study, we synthesized Silver nanoparticles (AgNPs) by using the leaf extract of Morus alba. Phytochemicals composition of M. alba was found the major reducing and stabilization agent during the synthesis of Ag nanoparticles. Different characterization techniques were performed for characterizing the synthesized nanoprticles. The results of X-ray diffraction (XRD) analysis revealed that the synthesized nanoparticles possess face centered cubic structure with size of $50 \mathrm{~nm}$ while scanning electron microscopic (SEM) analysis showed spherical shape. Fourier transform infrared spectroscopy (FTIR) analysis showed the presence of phytochemicals that behave as stabilization and reduction. Stability of synthesized nanoparticles upto a certain temperature was shown by thermo gravimetric analysis (TGA) analysis Photocatalytic behavior was examined by analysis the degrading potential of malachite green dye that revealed silver nanoparticles have efficient photocatalytic behavior. Significant antibacterial potential against Staphylococcus aureus $(14 \mathrm{~mm})$ than the Escherichia coli $(10 \mathrm{~mm})$ was shown by well diffusion method. Our findings suggested the synthesized nanoparticles are possess good potential as photocatalytic and antibacterial activity. The goal of synthesis of nanoparticles using plants and extracts is the best choice, because plants are nature's "chemical factories". They are cost efficient and require low preservation and have good potential.

Keywords: Biomass; Green dye; Malachite; Nanoparticles; Synthesis

\section{Introduction}

The synthesis of nanoparticles by using natural sources is attaining more attention due to various benefits like non-toxic, no undesirable side products, environment friendly, clean, safe and easily availability
[1]. Mostly green synthesis is more famous for metallic nanoparticles synthesis by using marine organism, plants extracts and microorganisms [2]. Recently synthesis by using plants extracts is getting more importance because of its ecofriendly 
nature, simplicity, easy availability and being more effective in pharmaceutical effects [3].

Stabilization of green synthesis was carried out at low temperature, low energy and renewal inputs according to green chemistry and green engineering. It is the major benefit of green synthesis and is alternative method as compared to physical and chemical methods of nanoparticles synthesis [4]. Reduction of Ag+ was performed by various methods including sodium in liquid ammonia [5], formaldehyde [6], ethylene glycol [7], glucose [8], N,N-dimethyl formamide [9], polyethylene glycerol [10] and sodium borohydride [11]. Moreover UV and $\gamma$-rays have also been used for the preparation of silver nanoparticles [12].

Silver is more attractive metal among all the noble metals and is effective and efficient antimicrobial agents which is used for ailment of various diseases [13], water and food verification [14]. Green synthesis of silver nanoparticles is widely used to synthesize nanoparticles to be used in different fields such as medicine, industry, electrochemical process [15], agriculture [16], biosensor $[17,18]$ and drug delivery [19].

Various techniques such as biological techniques [20], chemical [21] and radiation [22] are employed for silver nanoparticles synthesis. However still there is need to find to more ecofriendly and economical green synthesis techniques for the stabilization of AgNPs. The synthesis of nanoparticles by plants extract are more beneficial for the antibacterial activity at broad spectrum of bacterial strains [23]. Hence we carried out synthesis of the nanoparticles through $M$. alba leaf extract and efficiently used it for the removal of malachite green dye (MGD) from aqueous media.

\section{Materials and methods \\ Preparation of plant extract}

Fresh leaves of $M$. alba collected from the botanical garden of Govt. Post Graduate Islamia College, Gujranwala, washed with distilled water and dried under shade. $100 \mathrm{~g}$ of dried leaves were dissolved in the 1000 $\mathrm{mL}$ of double distilled water. Shaked the mixture for $48 \mathrm{hrs}$ and then filtered. The filtrate was then concentrated by using water bath at $60^{\circ} \mathrm{C}$. The semi liquid extract was acquired, which was kept at $4{ }^{\circ} \mathrm{C}$ for more usage.

\section{Synthesis of silver nanoparticles}

$20 \mathrm{~mL}$ of silver nitrate solution $(0.1 \mathrm{M})$ was mixed in $8 \mathrm{~mL}$ of plant extract slowly. As the silver nitrate solution was mixed with plant extract, the color of mixture was slowly changed from green to brownish. The change of color indicates the synthesis of silver nanoparticles. The mixture of nanoparticles was then subjected to lyopholize and dry nanoparticles ware obtained. This powdered sample was calcined in a furnace at $700^{\circ} \mathrm{C}$ to get pure silver nanoparticles synthesized from $M$. alba.

\section{Photocatalytic activity}

The photocatalytic activity of the silver nanoparticles was examined through the deprivation of MGD under sun light [24]. The dye solution was ready by dissolving $10 \mathrm{mg}$ of MGD powder in $1000 \mathrm{~mL}$ deionized water. $20 \mathrm{mg}$ of silver nanoparticles was mix with $40 \mathrm{~mL}$ of dye solution. The control setup was run parallel under the similar conditions without addition of AgNPs for the assessment of changes in color. The solution was stimulated for half hour and then exposed to sun light to sustain the equilibrium of silver nanoparticles in mixture. The temperature during experiment was restrained as $30^{\circ} \mathrm{C}$. $4 \mathrm{~mL}$ of the mixture was taken at an interval of 10 minutes and measure absorbance at $618 \mathrm{~nm}$ by UV/Vis spectrometer. The \% photocatalysis was calculated by

$\mathrm{D}=(1-\mathrm{Ct} / \mathrm{Co}) * 100 \%$

Where $\mathrm{D}$ is the \% degradation, Co is the equilibrium concentration before irradiation; $\mathrm{Ct}$ is the equilibrium constant after irradiation

\section{Antibacterial activity}

Antibacterial activity of synthesized silver nanoparticles was performed against two 
bacterial species Staphylococcus aureus and Escherichia coli by well diffusion assay [25]. $13 \mathrm{~g}$ of nutrient broth was melted in $1 \mathrm{~L}$ distilled $\mathrm{H}_{2} \mathrm{O}$ for media culture and standardized the solution monitored by autoclaved for 15 mints at $121^{\circ} \mathrm{C}$. The bacterial structure was intermixed with media culture and placed for shaking at $37^{\circ} \mathrm{C}$ for $24 \mathrm{hrs}$. The inoculums used in this experiment have $1 \times 108$ spores $/ \mathrm{mL}$ and was kept at $4{ }^{\circ} \mathrm{C}$. The plates (petri) were treated before transferring of media to inoculation $(100 \mu \mathrm{L} / 100 \mathrm{~mL})$ and then decanted. Then smaller filter discs were flatly laid down on growth media which confined $100 \mu \mathrm{L}$ of these synthesized nanoparticles and Rifmpacin which was used as standard. Now this media was allowed to cool for 24 hrs. The zone was formed which was measured by using zone reader.

\section{Results and discussion}

The silver nanoparticles were prepared using aqueous extract of $M$. alba according to reported procedure with little modification [26]. The synthesized nanoparticles were characterized by the standard techniques.

\section{FTIR spectroscopic analysis}

The determination of functional group was performed by FTIR analysis which showed the most probable biomolecules which are responsible for stabilizing and capping ability of silver nanoparticles synthesized by using $M$. alba extract. The figure 1 shows the FT-IR spectrum of the samples. The FT-IR spectrum indicates the intense absorption band around $3440 \mathrm{~cm}^{-1}, 1680$ $\mathrm{cm}-1$ and $1390 \mathrm{~cm}-1$ due to the stretching vibration of $\mathrm{O}-\mathrm{H}, \mathrm{H}-\mathrm{O}-\mathrm{H}$ bending vibration which is because of absorption of moisture, $-\mathrm{C}-\mathrm{O}$ and $-\mathrm{C}-\mathrm{O}-\mathrm{C}$ stretching modes, 1490 cm-1 (=N-H) and 1632 cm-1 (-N-H ) proposed the presence of terpenoids and alkaloids. A small peak at $680 \mathrm{~cm}-1$ was also absorbed, which may be attributed to existing of same biomolecule which are used as ligation agent that remained in the system even with repeated washing.

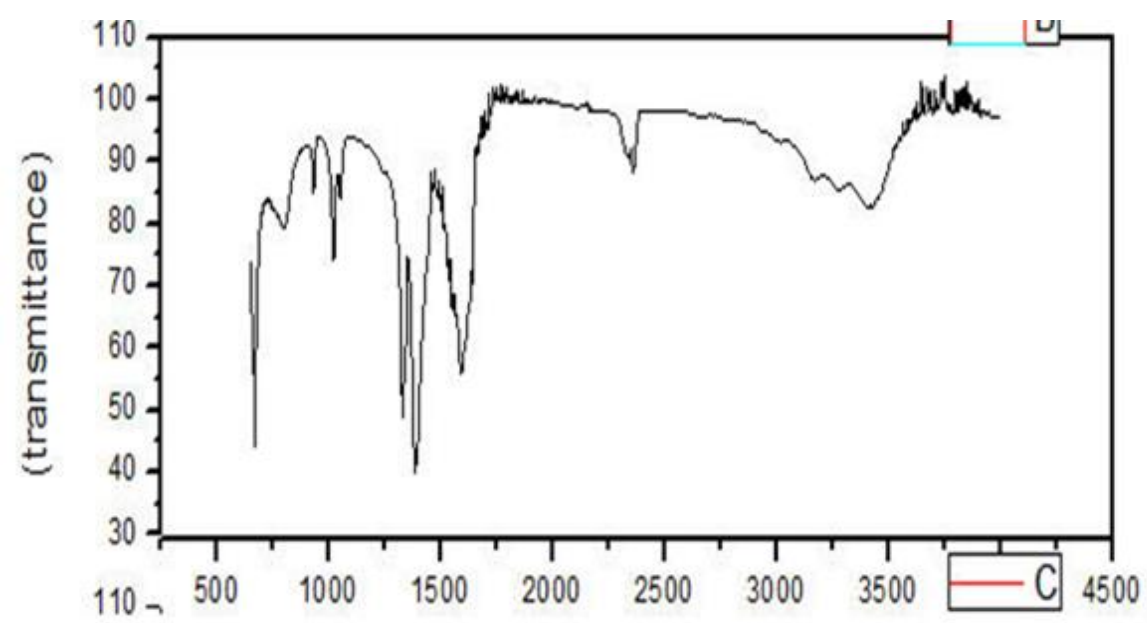

Figure 1. FT-IR spectrum of synthesized silver nanoparticles

\section{XRD analysis}

Figure 2 shows the XRD analysis of silver nanoparticles. The XRD analysis was carried out to study the crystalline structure of synthesized nanoparticles. A XRD peaks are observed at various $2 \theta$ values such as $38.14^{\circ}, 46.16^{\circ}$ and $76.46^{\circ}$ having plane reflections (111), (200) and (311). These are corresponding for the face centred cubic structure of synthesized silver nanoparticles. The most intense peak corresponding to the predominant orientation of silver nanoparticles is along (111) plane. Some extra peaks also observed that are low intensity peaks, which were considered because of the crystallization of bio-organic part on surface of synthesized silver nanoparticles. The crystalline size (D) was estimated by Scherrer's equation.

$\mathrm{D}=\mathrm{k} \lambda /(\beta(\cos \theta))$ 
In above equation $\mathrm{D}=$ particles sizes, $\mathrm{k}=$ Scherrer constant, $\lambda=$ wavelength, $\beta=$ broadening of peaks at full width the half

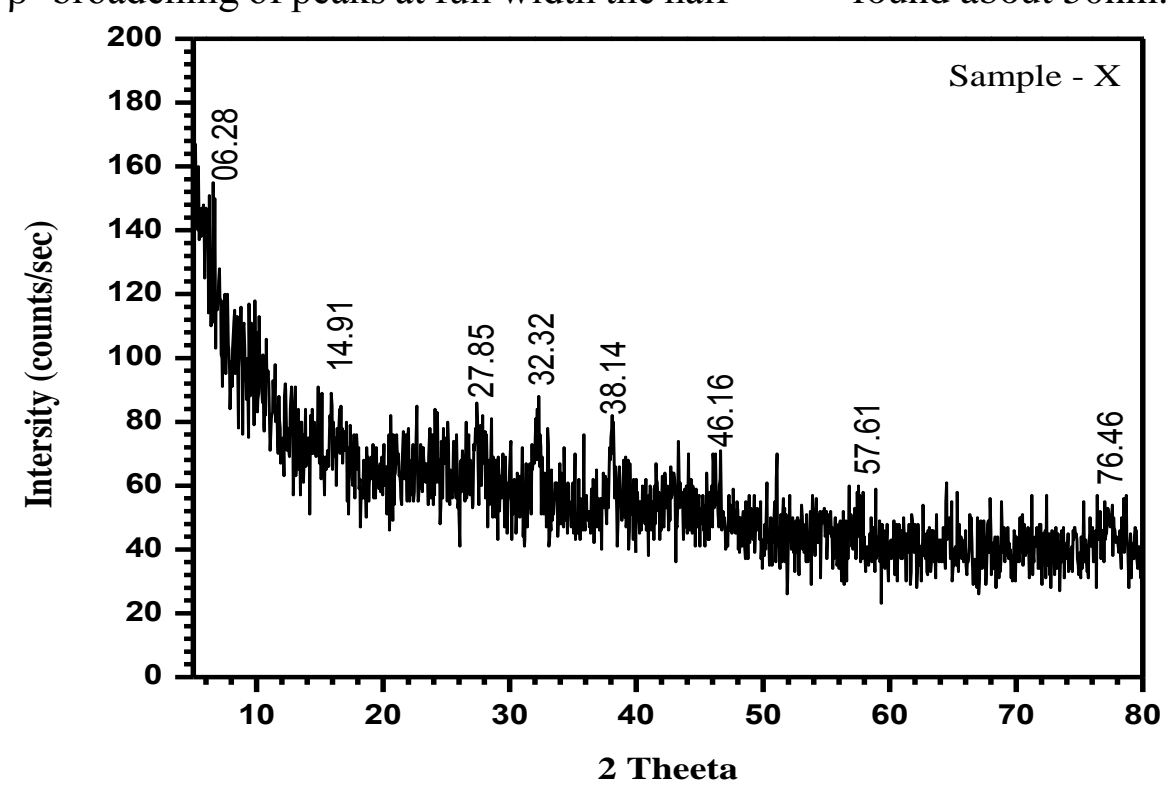

maximum in radius (FWHM) and $\Theta$ is the Bragg angle. The mean particle size was found about $50 \mathrm{~nm}$.

Figure 2. XRD graph of synthesized silver nanoparticles

\section{SEM analysis}

SEM analysis is most important characterization technique used to understand the surface properties and morphology of Ag nanoparticles. Figure 3a and $b$ showed the SEM analysis of synthesized silver nanoparticles by M. alba. Figure $3 \mathrm{a}$ and $\mathrm{b}$ confirms that all silver nanoparticles are inter connected, spherical in shape that seems to be forming open and porous network.

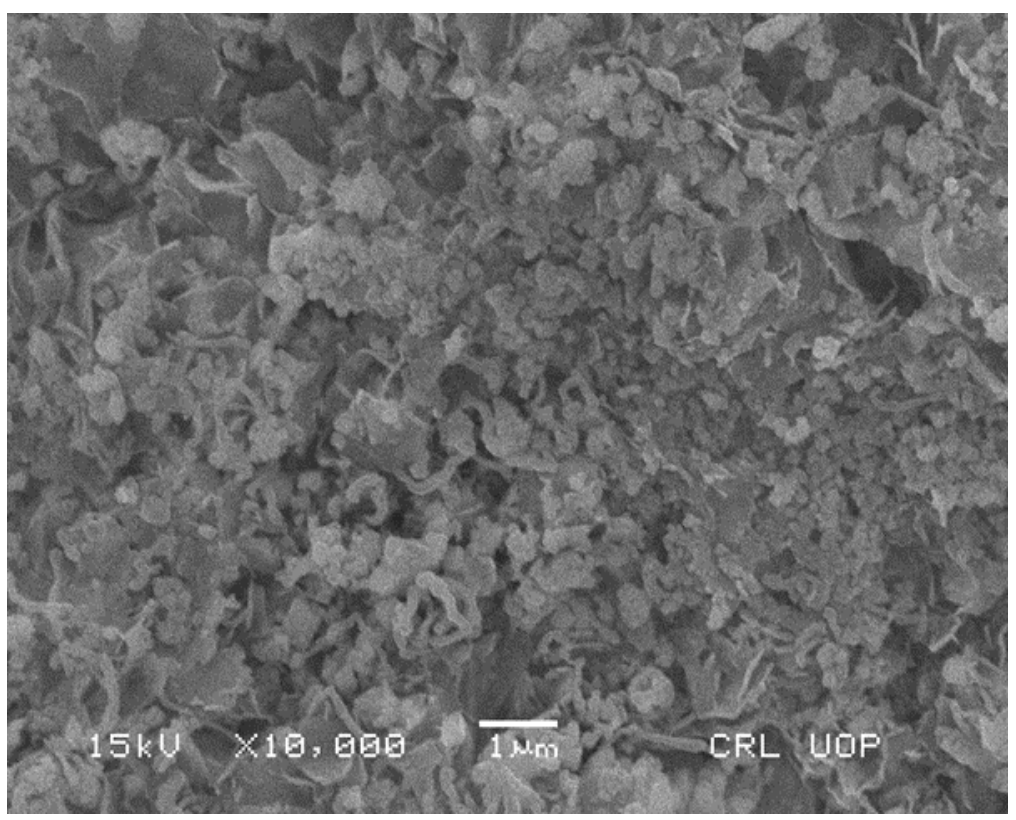

Figure 3(a). SEM image of synthesized silver nanoparticles 


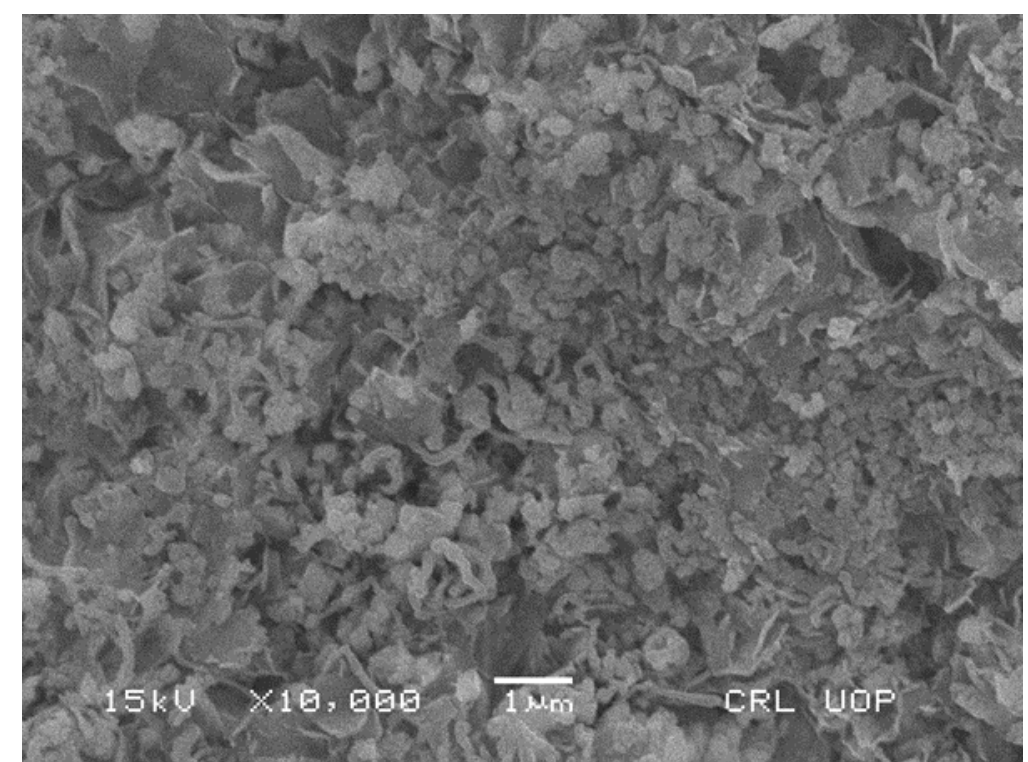

\section{Figure 3(b). SEM image of synthesized silver nanoparticles}

\section{Thermogravimetric analysis}

Thermal stability of synthesized silver nanoparticles by using $M$. alba was examined by TGA analysis which shows that nanoparticles began to degrade at about $280^{\circ} \mathrm{C}$ as described by (Figure 4). There is stability loss until at $800^{\circ} \mathrm{C}$, the total weight loss upto $800^{\circ} \mathrm{C}$ for silver nanoparticles was about $38.27 \%$. These results indicate the surface desorption of phytochemical compounds of plant extract which could be play an important role in reduction of silver ions that stabilize the particles in solution.

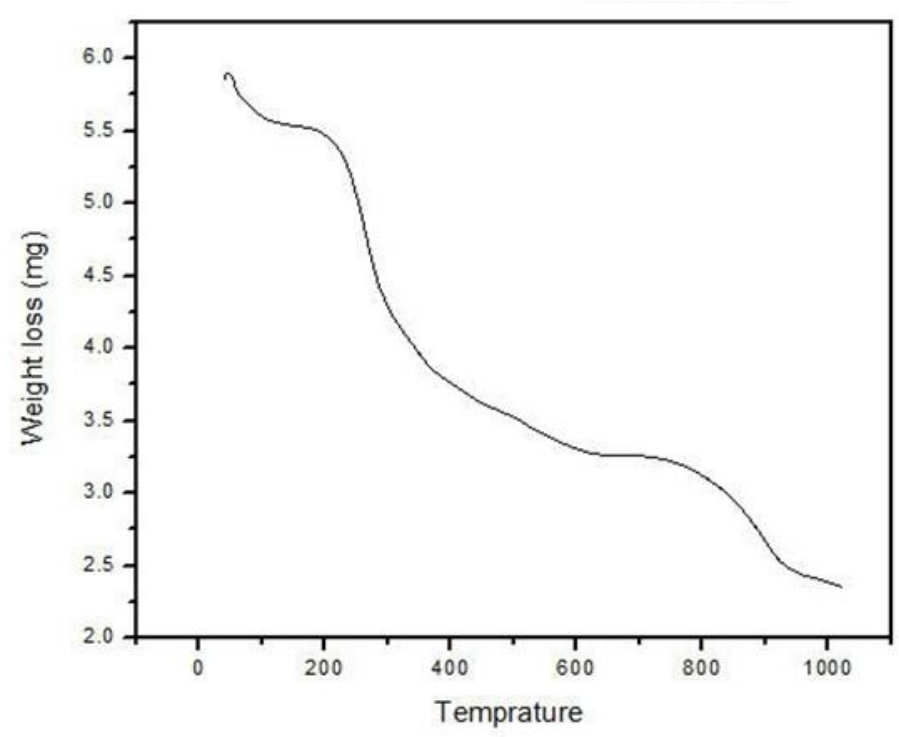

Figure 4. TGA analysis of synthesized silver nanoparticles

Antibacterial activity

Green synthesized silver nanoparticles were subjected to investigate the antibacterial activity against both gram positive ( $S$. aureus) and gram negative ( $E$. coli) bacteria by well diffusion method (Figure 5). The synthesized silver nanoparticles showed highest inhibition
$14 \mathrm{~mm}$ against the growth of $S$. aureus whereas inhibition $10 \mathrm{~mm}$ shown against E.coli. Antibacterial activity of standard used (rifmpacin) against $S$. aureous is $30 \mathrm{~mm}$ while against E.coli was estimated the synthesized silver nanoparticles showed less inhibition of growth of both testes bacterial strain as compared to standard 
used. The antibacterial efficacy of silver nanoparticles revealed the good antibacterial potential against gram positive bacteria as compared to gram negative bacteria. This may be related to the density of peptidoglycan layer that might be responsible for the inhibition of action of silver by the cells of bacteria. There are slight morphological changes of $S$. aureus and $E$. coli bacteria which might be due to differ in cells of respective cell wall. The peptidoglycan cell wall of $E$. coli is much thiner as compare to gram positive bacteria. As the cell wall of $S$. aureous is thicker than E.coli than it more important in the cell protection from the penetration of silver ion into the cytoplasm. So the antibacterial activity only effect when the silver ion release from there. These released silver ions enter in the cell wall and other cell, which turned DNA into condensed form, which react with protein at the same time. This mechanism might damage the bacterial strains or even lead to dead [27]. These results were also compared with the other reported studied. For example, Xiu et al. [28] reported the silver nanoparticles can slowly interact with protein on well of gram negative bacteria but this interaction was found rapid on well of gram negative bacteria due to coverage of extra layers on the well of gram negative bacteria. The aggregation of silver nanoparticles on the cell membrane and uptake on the inner side other bacterial strain like $P$. aeruginos $a$ and $S$. typhus.The results ware also compareable with the antibacterial potential of silver nanoparticles synthesized by using leaf extract of Parkiarox burghii that have higher antibacterial activity against $S$. aureus than E. coli [29].

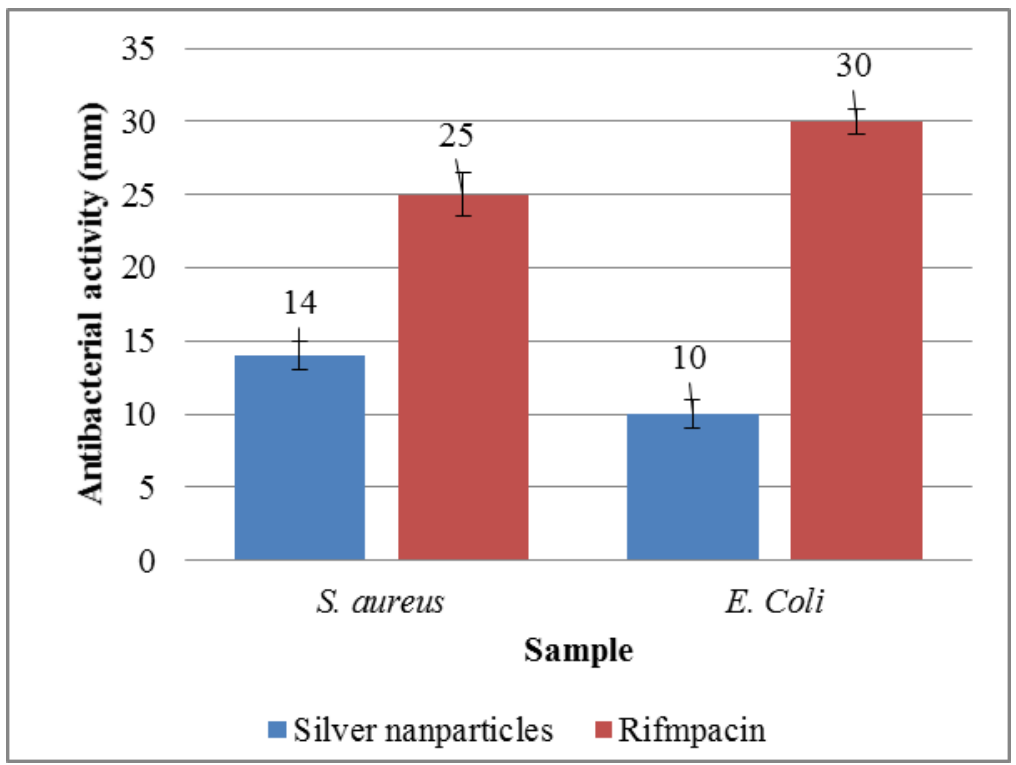

Figure 5. Antibacterial activity of synthesized silver nanoparticles

Photocatalytic degradation activity

Photocatalysis of degradation activity of nanomaterials has attaining more importance concerning environmental issues. Dyes pollutants and other organic compounds are releasing as waste products by the various industries which leaves harmful effects on human, animals as well as plants. MGD is very stable dye which is releasing by textile industry and it possess aromatic structure compounds. It has more resistant to heat and light. As it is more stable and has toxic effects, so its removal from environment is necessary. In present research work, MGD was degraded by using synthesized silver nanoparticles. The characteristic peak of MGD was determined at $618 \mathrm{~nm}$ which is further used for the assessment of photocatalytic 
degradation of MGD. Results showed that as the contact time was kept increases, the percentage degradation was also increases. The results also revealed that degradation of MGD due to the presences of photocatalyst. The fact behind this degradation is that light irradiation assisted the electron hole pair generation which are responsible for the enhancement of oxidation and reduction process with the MGD. The result also proves that silver nanoparticles have effective catalytic potential for the reduction of MGD, it suggested that photocatlytic activity is positively related with the surface area. As the size of silver nanoparticle decreases the number of coordinated $\mathrm{Ag}$ atom is increases that enhanced the adsorption of reactant MGD on the catalyst surface and smooth the progress of the reduction. Many factors such as light absorption, contact time, $\mathrm{pH}$ and temperature etc play significant effect on the photocatalytic degradation (Figure 6). Sphere structure and particle size also effect on the degradation activity of silver nanoparticles as the size increases, more active side and surface area increases which enhance the binding area. Previous scientific literature also proves the similar trends of factors influence [30].

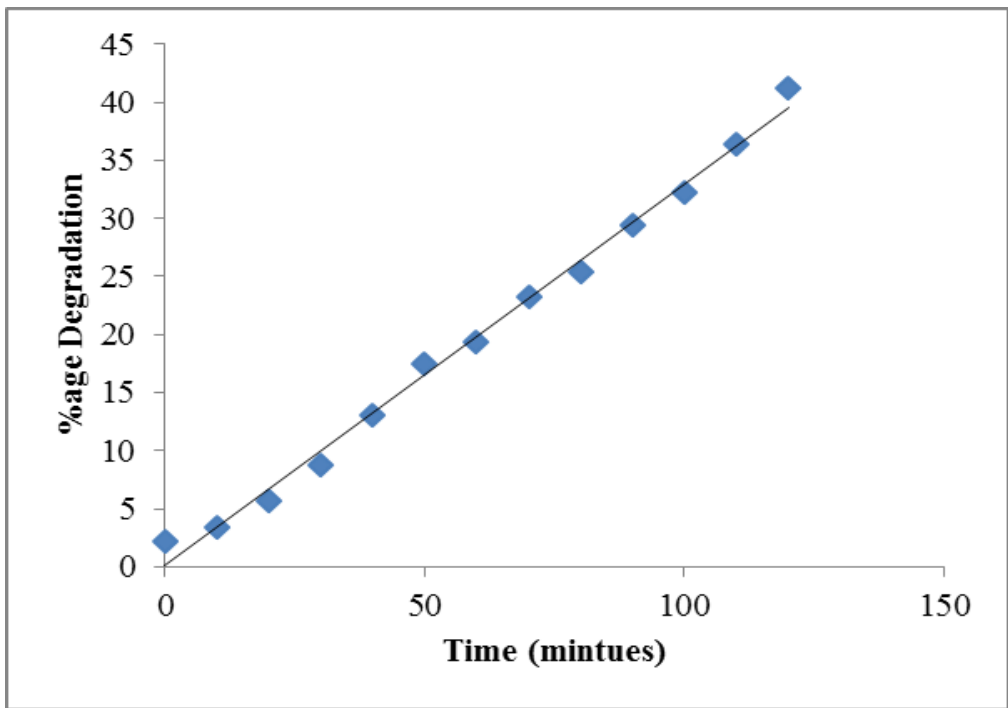

\section{Figure 6. \% degradation of synthesized silver nanoparticles}

\section{Conclusion}

Synthesis of bio-inspired nanomaterials is attaining more attention due to use of less harmful reagents and provide more effective products in beneficial approaches. These showed more ecofriendly less time consuming, more compatibles, easily availability and low cost. Herein, green synthesis of silver nanoparticles having size $50 \mathrm{~nm}$ was successfully done by the reaction of silver nitrate with leaf extract of M. alba. Change of colour of solution during the experiment showed the formation of silver nanoparticles. The phytochemical present in the plants extract was found responsible for the reduction of silver ions which lead to the synthesis and stabilization of silver nanoparticles. The photocatalytic degradation activity of synthesized nanoparticles showed that these effectively degrade the MGD nanoparticles in the presence of sun light. The photocatalytic degradation was increase with the increase of contact time of nanoparticle with the solution in the presence of sunlight. The result of photo degradation suggested their usage in dye effluent treatment and purificantion systems. Antibacterial activity also showed significant results $(14 \mathrm{~mm}$ and $10 \mathrm{~mm})$ against both $S$. aureus and E. coli bacterial strains respectively). The present study revealed that the potential of $M$. Alba on the synthesis of silvernanoparticles and evaluation of antibacterial activity represented a significant advancement of 
nanomaterials possessing the realistic implications.

\section{Authors' contributions}

Conceived and designed the experiments: M Arshad, MA Shaheen, A Qayyum \& M Maqsood, Performed the experiments: $M$ Arshad \& A Qayyum, Analyzed the data: M Arshad, A Karim \& T Ahmad, Contributed reagents/ materials/ analysis tools: $\mathrm{M}$ Arshad \& A Qayyum, Wrote the paper: M Arshad \& MA Shaheen \& T Mehmood.

\section{References}

1. Velusamy P, Das J, Pachaiappan R \& Vaseeharan B (2015). Greener approach for synthesis of antibacterial silver nanoparticles using aqueous solution of neem gum (Azadirachta indica L). Pandian, Ind Crops Products 66: 103109.

2. Santhoshkumar T, Rahuman AA, Rajakumar G, Marimuthu S, Bagavan A, Jayaseelan C, Zahir AA, Elango G \& Kamaraj C (2011). Synthesis of silver nanoparticles using Nelumbo nucifera leaf extract and its larvicidal activity against malaria and filariasis vectors. Parasitology Res. 108(3): 693-702.

3. Shalaka AM, Pratik RC, Vrishali BS \& Suresh PK (2011). Rapid Biosynthesis of Silver Nanoparticles Using Cymbopogan Citratus (Lemongrass) and its Antimicrobial Activity. Nano Micro Letters 3(3): 189-194.

4. Nishida N, Yao H, Ueda T, Sasaki A \& Kimura K (2007). Synthesis and Chiroptical Study of D/L-PenicillamineCapped Silver Nanoclusters. Chem of Materials 19(11): 2831-2841.

5. Shameli K, Ahmad MB, Yunus WMZW, Rustaiyan A, Ibrahim NA, Zargar M \& Abdollahi Y (2010). Synthesis and characterization of silver/talc nanocomposites using the wet chemical reduction method. Inter $J$ Nanomedicine 5: 875-887.

6. Mandal A, Meda V, Zhang WJ \& Dalai AK (2012). Spectroscopic investigation of collagen scaffolds impregnated with AgNPs coated by PEG/TX-100 mixed systems. Inter J Bio Macromolecules 50(3): 603-612.
7. Zhang Y, Chen F, Zhuang J, Tang Y, Wang D, Wang Y, Dong A \& Ren N (2002). Synthesis of silver nanoparticles via electrochemical reductio $\mathrm{n}$ on compact zeolite film modified electrodes. Chemical Communi 23: 28142815.

8. Kheybari S, Samadi N, Hosseini SV, Fazeli A \& Fazeli MR (2010). Synthesis and antimicrobial effects of silver nanoparticles produced by chemical reduction method.DARU J Pharma Sci 18(3): 168-172.

9. Shameli K, Ahmad MB, Zargar M, Yunus WMZW, Rustaiyan A \& Ibrahim NA (2011). Synthesis and characterization of silver/montmorillonite/chitosan

bionanocomposites by chemical reduction method and their antibacterial activity. Inter J Nanomedicine 6: 581590.

10. Shameli K, Ahmad MB, Yunus WZW, Ibrahim NA \& Darroudi M (2010). Green Process for Impregnation of Silver Nanoparticles into Microcrystalline Cellulose and Their Antimicrobial Bionanocomposite Films. Inter $J$ of Nanomedicine 5: 743-751.

11. Shameli K, Ahmad MB, Zargar M, Yunus WMZW \& Ibrahim NA (2011). Synthesis of silver nanoparticles in montmorillonite and their antibacterial behavior. Inter J Nanomedicine 6: 331341.

12. Setua P, Pramanik R, Sarkar S, Ghatak C, Das SK \& Sarkar N (2010). Synthesis of silver nanoparticle inside the nonaqueous ethylene glycol reverse micelle and a comparative study to show the effect of the nanoparticle on the reverse.The J. Physical Chem B 114(22): 7557-7564.

13. Kumar DA, Palanichamy V \& Roopan SM (2014). Green synthesis of silver nanoparticles using Alternanthera dentata leaf extract at room temperature and their antimicrobial activity. Spectro Acta Part A: Molecu Bio Spectro 127: 168-171.

14. Haes AJ \& Van Duyne RP (2002). A nanoscale optical biosensor: sensitivity 
and selectivity of an approach based on the localized surface plasmon resonance spectroscopy of triangular silver nanoparticles. $J$ Ameri Chemi Soc 124(35): 10596-10604.

15. Patil RS, Kokate MR \& Kolekar SS (2012). One-pot synthesis of PVAcapped silver nanoparticles their characterization and biomedical application. Spectro Acta Part A: Molecu Biomole Spectro 91: 234-238.

16. Dankovich TA \& Gray DG (2011). Bactericidal Paper Impregnated with Silver Nanoparticles for Point-of-Use Water Treatment. Envir Sci \& Tech 45(5): 1992-1998.

17. Chaudhry Q \& Castle L (2011). Nanotechnology in Agriculture and Food Science. Trends in Food Sci \& Tech 22(11): 595-603.

18. Frederix F, Friedt JM, Choi KH, Laureyn W, Campitelli A, Mondelaers D, Maes G \& Borghs $G$ (2003). Biosensing based on light absorption of nanoscaled gold and silver particles.Anal Chem 75(24): 68946900.

19. Kelly FM \& Johnston JH (2011). Colored and functional silver nanoparticle-wool fiber composites. ACS A Materials \& Inter 3(4): 10831092.

20. Rajan R, Chandran K, Harper SL, Yun SI \& Kalaichelvan PT (2015). Plant extract synthesized silver nanoparticles: An ongoing source of novel biocompatible materials. Ind Crops Products 70: 356-373.

21. Maneerung $T$, Tokura $S \&$ Rujiravanit $R$ (2008). Impregnation of silver nanoparticles into bacterial cellulose for antimicrobial wound dressing. Carbo Polymers 72(1): 43-51.

22. Marini M, De Niederhausern S, Iseppi R, Bondi M, Sabia C, Toselli M \& Pilati F (2007). Antibacterial activity of plastics coated with silver-doped organicinorganic hybrid coatings prepared by sol-gel processes. Biomacro 8(4): 12461254.
23. Ahmed S, Ahmad M, Swami BL \& Ikram S (2016). A review on plants extract mediated synthesis of silver nanoparticles for antimicrobial applications: A green expertise. $J A d v$ Res 7(1): 17-28.

24. Tahir K, Nazir S, Li B, Ahmad A, Nasir T, Khan AU, Shah SAA, Khan ZUH, Yasin G \& Hameed MU (2016). HameedSapium sebiferum leaf extract mediated synthesis of palladium nanoparticles and In- Vitro investigation of their bacterial and photocatalytic activities. J Photochem Photobio B: Bio 164: 164-173.

25. Jiang $\mathrm{Y}$, Zhu CF, Zheng Z, He JB \& Wang Y (2016). Influence of silver nanoparticles on heavy metals of pore water.Inor Chimica Acta 45: 143-147.

26. Krishnaraj C, Jagan EG, Rajasekar S, Selvakumar P, Kalaichelvan PT \& Mohan N (2010). Synthesis of silver nanoparticles using Acalypha indica leaf extracts and its antibacterial activity against water borne pathogens. Colloids Sur B: Bio 76(1): 50-56.

27. Feng QL, Wu S, Chen GQ, Cui FZ, Kim TN \& Kim JO (2000). A mechanistic study of the antibacterial effect of silver ions on Escherichia coli and Staphylococcus aureus. J Biomed Mater Res 52: 662-668.

28. Xiu ZM, Zhang QB, Puppala HL, Colvin VL \& Alvarez PJJ (2012). Negligible particle-specific antibacterial activity of silver nanoparticles. Nano Lett 12: 4271 4277

29. Paul B, Bhuyan B, Purkayastha DD \& Dhar SS (2016). Photocatalytic and antibacterial activities of gold and silver nanoparticles synthesized using biomass of Parkia roxburghii leaf. J Photochem Photobio B Bio 154: 1-7.

30. Roy N, Mondal S, Laskar RA, Basu S, Mandal D \& Begum NA (2010). Biogenic synthesis of $\mathrm{Au}$ and $\mathrm{Ag}$ nanoparticles by Indian propolis and its constituents. Colloids Surf B: Biointerfaces 76(1): 317-325. 